\title{
THERMAL NEUTRON-ACTIVATION ANALYSIS OF TITANIUM USING 5-8-MINUTE TITANIUM-51 AND RAPID RADIOCHEMICAL SEPARATIONS
}

\author{
Chong Kur Kim* and W. Wayne MeinKe \\ Department of Chemistry, University of Michigan, Ann Arbor, Michigan, U.S.A.
}

(Received 16 August 1962. Accepted 7 September 1962)

\begin{abstract}
Summary-A nuclear reactor has been used to determine trace amounts of titanium by neutron-activation analysis in a variety of samples. A 10-min radiochemical separation procedure coupled with gamma-ray spectrometry permitted measurement of $5 \cdot 8$-min titanium-51. With a neutron flux of about $10^{12}$ neutrons. $\mathrm{cm}^{-2} \cdot \mathrm{sec}^{-1}$ the practical lower limit of detection was about $6 \times 10^{-7} \mathrm{~g}$ of titanium.
\end{abstract}

\section{INTRODUCTION}

TRACE quantities of many elements have been analysed by neutron-activation analysis but little work has been reported to date on titanium. This lack of interest is undoubtedly related to the fact that only one radioactive isotope, $5 \cdot 8-\mathrm{min}{ }^{51} \mathrm{Ti}$, is formed by the $(\eta, \gamma)$ reaction on the titanium isotopes. Reports have been published ${ }^{1,2}$ on a low sensitivity determination of titanium by the $(n, p)$ reaction using fast neutrons to produce long-lived scandium isotopes, but little work has been done with the shortlived ${ }^{\mathrm{b}} \mathrm{Ti}$.

The calculated sensitivity for production of this short-lived isotope indicates ${ }^{3}$ that the $(\mathrm{n}, \gamma)$ activation of titanium does not produce the ultra high sensitivity possible with elements such as silver and vanadium, but nonetheless submicrogram quantities of titanium can easily be determined. Although colorimetric methods are reported ${ }^{4}$ which also approach this level of sensitivity, serious interferences from other elements in the sample often arise. Similarly, corrections for "reagent blanks" become quite appreciable at these levels.

The nuclear characteristics of the titanium $(\mathrm{n}, \gamma)$ activation give little promise for non-destructive analysis of samples using only scintillation spectrometry. On the other hand, rapid radiochemical procedures can be designed to separate titanium from other activated contaminants and thus permit the analysis of this element on a time scale of a few min.

This study is one of several ${ }^{5,8}$ which have been made with the facilities of the Ford Nuclear Reactor at the University of Michigan to explore the use of short-lived radioisotopes in activation analysis. These rapid activation and measurement facilities have been coupled with rapid radiochemical separations to determine titanium (by $5 \cdot 8-\mathrm{min}{ }^{51} \mathrm{Ti}$ ) in a variety of samples.

\section{Apparatus}

\section{EXPERIMENTAL}

Powdered samples sealed in pharmaceutical-type gelatin capsules were irradiated in nylon snaptype "rabbits" in the pneumatic tube system of the Ford Nuclear Reactor of the University of Michigan. This system permits irradiations at thermal neutron fluxes of about $10^{12}$ neutrons $/ \mathrm{cm}^{2} / \mathrm{sec}^{1}$ (at

* Present address: Atomic Energy Research Institute, Seoul, Korea. 
full power of $1 \mathrm{MW}$ ) and delivery to a hood within $3 \mathrm{sec}$ after the end of irradiation. Samples were then worked up chemically and were measured by a $3^{\prime \prime} \times 3^{\prime \prime} \mathrm{NaI}(\mathrm{TI})$ crystal coupled to a 100-channel pulse-height analyser with duplicate memories. This equipment has been described in detail elsewhere. ${ }^{\text {-10 }}$

\section{Preparation of samples}

A number of typical samples were analysed to test the general applicability of the radiochemical separation procedure. Biological ash samples had been prepared by igniting dried marine organisms in a quartz crucible at a temperature below $550^{\circ} .11$ There was no prior preparation for the tobacco and leaf samples. Rock samples and some meteorite samples were ground to a fine powder by an extremely clean agate mortar and pestle. The G-1 and W-1 samples were obtained in powdered form from the U.S. Geological Survey.

The weighed samples were placed in a gelatin capsule and surrounded with clean tissue. These were then irradiated in the "rabbit" together with a weighed gold monitoring foil for a period of 15 min at full power. Care was taken that foil and sample were placed in reproducible positions relative to the reactor core because in our reactor facility neutron fluxes can vary by as much as $30 \%$ from one side of the rabbit to the other. ${ }^{7}$

\section{Radiochemical separations*}

Rocks, minerals and meteorites. During the irradiation, carrier solution containing $0.80 \mathrm{mg}$ of titanium (prepared by dissolution of titanium oxide in concentrated sulphuric acid and diluting) was evaporated to dryness in a nickel crucible and 4-5 g of sodium peroxide added. About $0.1 \mathrm{~g}$ of finely* ground irradiated sample (still in gelatin capsule) was then added, the lid placed tightly on the crucible, and the mixture fused for $1 \mathrm{~min}$. The outside of the crucible was then cooled by dipping into a beaker of cold water and the melt made to solidify in a thin readily dissolved coating by manipulation of the crucible.

The melt was dissolved in water, the solution boiled, and the resulting precipitate centrifuged in a $50-\mathrm{ml}$ cone. This precipitate, which includes all of the titanium, was acidified with either hydrochloric acid or with sulphuric acid, iron carrier added and the solution made alkaline with ammonia to precipitate the iron and titanium. This was also centrifuged and the supernate drawn off. To the residue were added, successively, $20 \mathrm{ml}$ of $4 M$ sulphuric acid, $10 \mathrm{ml}$ of $6 \%$ (by weight) aqueous cupferron, and $10 \mathrm{ml}$ of isopropyl ether. The mixture was shaken vigorously and the quadrivalent titanium extracted into the organic layer. At this point a crushed ice bath must be used to keep the liquids cool or the cupferron will be destroyed and the extraction will become ineffective. The aqueous layer was drawn off and discarded. When copper, vanadium, molybdenum and tungsten are present in large amounts in the irradiated sample, they can be eliminated by washing the ether with $20 \mathrm{ml}$ of cooled $5 M$ sodium hydroxide. Ten $\mathrm{ml}$ of the ether is then rewashed twice with $4 M$ sulphuric acid and transferred to a marked tube for measurement with the gamma-ray spectrometer.

The entire procedure can be completed in about $10 \mathrm{~min}$ with an average recovery of about $70 \%$ for the titanium.

Biological samples. For botanical and biological samples it was usually sufficient to leach the sample in a 250 -ml beaker with concentrated nitric acid containing the titanium carrier. The mixture was heated nearly to dryness, then $2 \mathrm{ml}$ of $72 \%$ perchloric acid added, and the sample fumed to eliminate the last of the organic matter and most of the iodine. Concentrated hydrochloric acid was added and the solution clarified by heating. Iron carrier was then added and the solution made alkaline with sodium hydroxide to precipitate $\mathrm{Fe}\left(\mathrm{OH}_{8}\right)$ and $\mathrm{TiO}_{2}$. The precipitate was centrifuged and the supernate drawn off. The precipitate was then dissolved in sulphuric acid and the cupferron extraction applied as above.

The hydroxide precipitation can be eliminated if the sample does not contain a large amount of any one inorganic matrix species. Iodine is a rather significant problem in handling marine organisms, however, and the hydroxide precipitation does give some decontamination from this element. A preliminary carbon tetrachloride extraction step could also be used at this point to eliminate much of the iodine, but it must be repeated at least twice to be effective. Fuming expels much of the iodine, but it also can cause considerable contamination on the inside of the hoods.

Fusion with $\mathrm{Na}_{2} \mathrm{O}_{2}, \mathrm{Na}_{2} \mathrm{~S}_{2} \mathrm{O}_{7}, \mathrm{NaHSO}_{3}$, or $\mathrm{KHF}_{2}$ in a platinum crucible can be substituted for the acid leach above if desired. The melt is then dissolved in concentrated sulphuric acid and water.

\section{Activity determination}

The garmma-ray spectrum for ${ }^{51} \mathrm{Ti}$ shows several peaks of which the $0.323-\mathrm{Mev}$ peak is by far the

* Other information on radiochemical procedures for titanium is available in the monograph The Radiochemistry of Titanium. ${ }^{12}$ 
most prominent (Fig. 1). Spectra were obtained in the energy range of about 0-0.5 Mev as shown in Fig. 2 and the amount of ${ }^{51}$ Ti determined from the area under the 0.323-Mev photopeak. Background and interfering Compton radiations from other activities remaining in the sample were eliminated by extrapolation of the base line from both sides of the photo peak. A total photopeak area of $100 \mathrm{cpm}$ was considered to be the practical limit of detection.

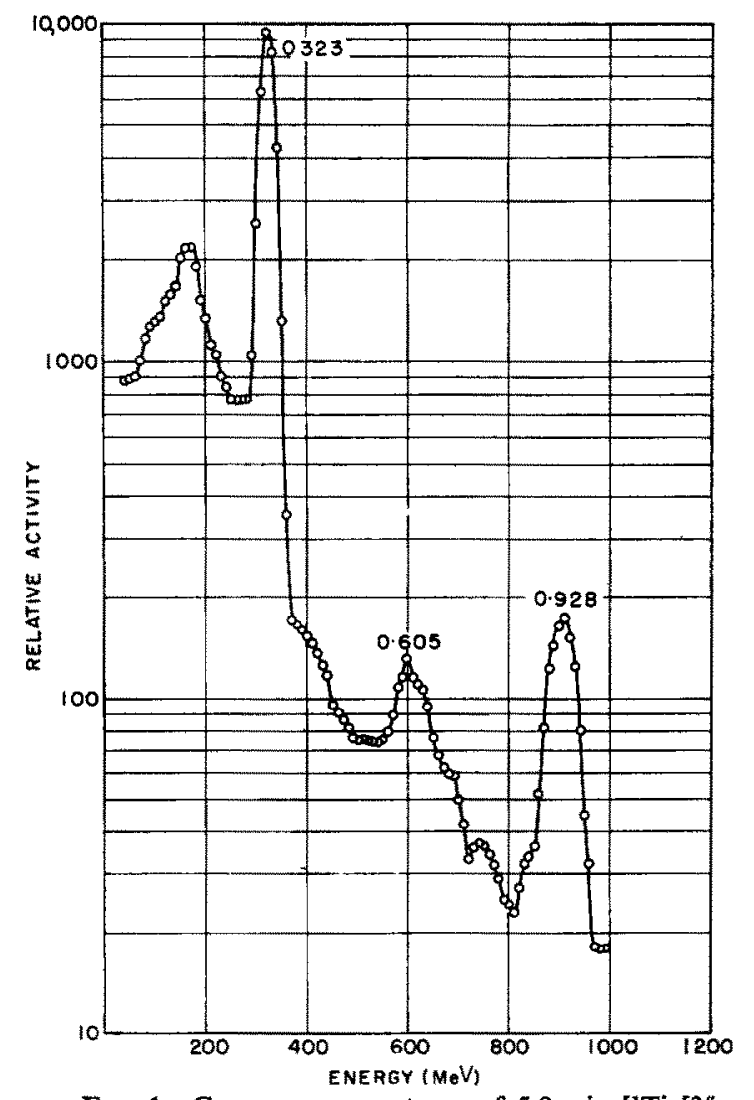

Fig. 1-Gamma-ray spectrum of $5 \cdot 8-\mathrm{min}{ }^{51} \mathrm{Ti}\left[3^{\prime \prime} \times\right.$ 3 " $\mathrm{NaI}(\mathrm{Tl})$ crystal; source distance, $0.5 \mathrm{~cm}$ ].

\section{Monitoring procedures}

Gold foils weighing between 0.1 and $0.2 \mathrm{mg}$ were taped to the inside of the cap of the "rabbit". Following irradiation, the foils were set aside for 2 days for decay, then counted in a gamma scintillation well counter. All irradiations were normalised to a neutron flux of $1 \times 10^{12}$ neutrons. $\mathrm{cm}^{-2} \cdot \mathrm{sec}^{-1}$ by comparison with other measurements made with calibrated gold foils.

\section{Chemical yield determination}

The weight of titanium in the counting sample was obtained colorimetrically using the yellow colour of pertitanate. The ether counting sample was evaporated to dryness, $5 \mathrm{ml}$ of concentrated nitric acid added and the solution again heated to near dryness. Five $\mathrm{ml} \mathrm{of} 72 \%$ perchloric acid were then added and fumed off until the colour from the sample had completely disappeared. After the sample had cooled, $10 \mathrm{ml}$ of $10 \%$ sulphuric acid were added along with $5 \mathrm{ml} \mathrm{of} 3 \%$ hydrogen peroxide to form the pertitanate colour. The total volume of the solution was made up to $50 \mathrm{ml}$ in a volumetric flask. Samples without added titanium carrier were used for reagent blanks.

\section{DISCUSSION}

The gamma ray spectrum of ${ }^{51} \mathrm{Ti}$ (Fig. 1) shows three photopeaks of $0.32,0.60$, and $0.93 \mathrm{Mev}$. The two higher energy peaks, however, are hardly detectable in practical samples containing less than $10^{-4} \mathrm{~g}$ of titanium as shown in Fig. 2. 
Since the $0.32-\mathrm{Mev}$ photopeak is the only one available for detection of the element by gamma spectrometry, considerable interference is encountered from the Compton scatter of higher energy peaks of contaminating materials. Thus non-destructive analyses would be very difficult or impossible for most samples, and good radiochemical separations are very important for activation analysis of this element.

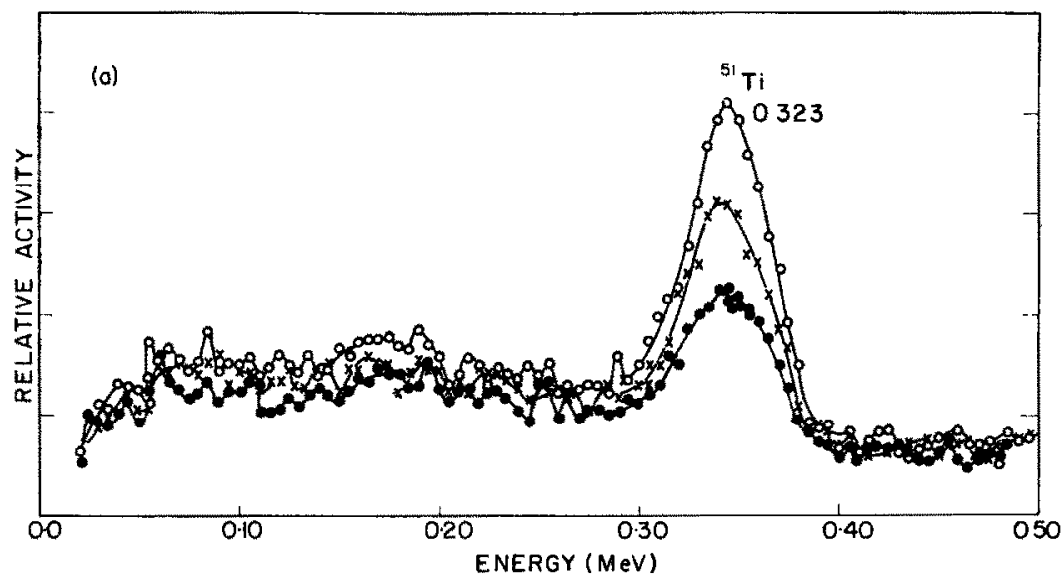

FIG. 2.-Gamma-ray spectra of titanium fraction separated from marine biological ash sample:

(A) Spectra taken at 3-min intervals.

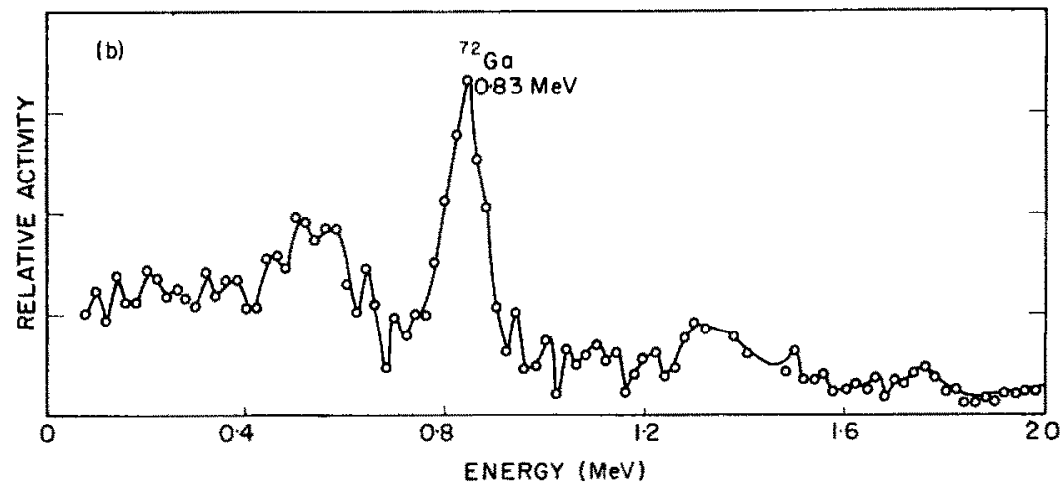

(B) ${ }^{12} \mathrm{Ga}$ contamination after short-lived ${ }^{\mathrm{s}} \mathrm{Ti}$ has decayed out.

In addition to providing satisfactory decontamination, the separation must be completed before the activity of the $5 \cdot 8-\mathrm{min}{ }^{51} \mathrm{Ti}$ has decayed out. A number of procedures were tested in this study and are summarised in the monograph on The Radiochemistry of Titanium. ${ }^{12}$ An extraction with tri-octyl phosphine oxide (TOPO) in hexane gave somewhat more selectivity than the cupferron procedure, but it took a prohibitive 17-20 min. Oxine extractions were found unsatisfactory because this reagent is selective only at a specific $\mathrm{pH}$ level, and additional time was spent adjusting the $\mathrm{pH}$ of the solution.

The radiochemical separations outlined above proved to be the most applicable. Depending upon the type of sample, some of the steps in the separation can be omitted. For example, unless a large amount of vanadium is contained in the sample, the sodium hydroxide backwash is unnecessary because most of the vanadium is eliminated as 
sodium vanadate (dissolved in water when the sodium peroxide melt is treated with water and centrifuged). However, if there is a large amount of vanadium in the sample, a trace of vanadium precipitating with the titanium will interfere with the colorimetric determination of the titanium carrier. The sodium hydroxide backwashing eliminates vanadium very well, but it also reduces the chemical recovery of titanium appreciably.

The temperature should be kept low (about $10^{\circ}$ ) preceding the sodium hydroxide

TABtE I.--ACTIVATION ANALYSIS FOR TITANIUM IN A MARINE ORGANISM [ASHES OF Pandalus sp. (PRAWN SOFT PARTS) COLLECTED NEAR JAPAN $\left.{ }^{i 1}\right]$

\begin{tabular}{ccccc}
\hline Sample & $\begin{array}{c}\text { Amount } \\
\text { irradiated, } \\
g\end{array}$ & $\begin{array}{c}\text { Yield of } \\
\text { radiochemical } \\
\text { separation, } \\
\%\end{array}$ & $\begin{array}{c}\text { Ti found, } \\
g\end{array}$ & $\begin{array}{c}\text { Level of Ti in sample, } \\
p p m\end{array}$ \\
\hline 1 & 0.2088 & 71 & $8.5 \times 10^{-8}$ & $40 \cdot 3$ \\
2 & 0.2365 & 73 & $9.8 \times 10^{-6}$ & $41 \cdot 3$ \\
3 & 0.2772 & 65 & $1.15 \times 10^{-5}$ & $41 \cdot 4$ \\
4 & 0.2842 & 68 & $1.16 \times 10^{-5}$ & $40 \cdot 4$ \\
5 & 0.2944 & 66 & $1.26 \times 10^{-5}$ & 42.6 \\
6 & 0.3208 & 69 & $1.17 \times 10^{-5}$ & 36.4 \\
\cline { 3 - 4 } & & & & Average 40.4 $\pm 2.2^{*}$ \\
\hline
\end{tabular}

* Error is "standard deviation"

backwashing and the aqueous layer should be removed immediately after the shaking to prevent decomposition of the cupferron reagent. The iron precipitation step is often not necessary unless considerable copper is present in the sample. Copper is a rather serious contaminant if it precipitates with titanium because it has a $0.51-\mathrm{MeV}$ annihilation peak near the $0 \cdot 32-\mathrm{Mev}$ titanium peak. The sodium hydroxide backwash step also eliminates copper.

Isopropyl ether is superior to chloroform as the solvent in the cupferron extraction because the two separated layers appear immediately. Where possible, two sulphuric acid washes should be used to eliminate mechanical contamination accompanying the solvent extraction. Care must also be taken to separate cleanly and completely the aqueous layer from the ether layer.

In its simplest form of one cupferron extraction and a double sulphuric acid wash, this procedure can be completed in $8 \mathrm{~min}$ on a sample such as an aluminium alloy with a yield of about $92 \%$.

Calibration curves were taken under several conditions of measurement of the ${ }^{51} \mathrm{Ti}$ gamma rays. In the standard procedure the $10 \mathrm{ml}$ of ether extractant were counted directly in a 1-in. $\times 6$-in. tube because of the limited time of separation $(9 \mathrm{~min})$. When the tube was brought close to the crystal, counting geometries of $20-22 \%$ were obtained. Somewhat higher sensitivities can be obtained if the sample is transformed into a dry layer for measurement near the crystal. The ether can be evaporated on the bottom of a $150-\mathrm{ml}$ beaker which is then attached to the crystal; or the sample can actually be precipitated on a Whatman No. 42 filter paper which is then measured on the top shelf. These latter techniques gave counting geometries of about $40 \%$ but were time consuming, and thus the simple counting of the ether solution was adopted as the standard procedure. By this technique a photopeak area of $100 \mathrm{cpm}$ is obtained with about $0.6 \mu \mathrm{g}$ of titanium. 
Results obtained from the activation analysis of marine organisms are summarised in Table I and give a general indication of the precision obtainable with this method. Successive spectra similar to those of Fig. 2 were obtained with these samples. Results obtained with small amounts of three types of standard samples are given in Table II. An additional number of analyses are summarised in Table III.

TABLE II-ACTIVATION ANALYSIS OF ROCKS AND ALLOY FOR TITANIUM

\begin{tabular}{|c|c|c|c|c|c|}
\hline Sample & $\begin{array}{c}\text { Amount } \\
\text { irradiated, } \\
g\end{array}$ & $\begin{array}{c}\text { Yield of } \\
\text { radiochemical } \\
\text { separation, } \\
\%\end{array}$ & $\begin{array}{c}\text { Ti found, } \\
g\end{array}$ & $\begin{array}{l}\text { Level of } \mathrm{Ti} \\
\text { in sample, } \%\end{array}$ & $\begin{array}{c}\text { Values } \\
\text { reported }\end{array}$ \\
\hline $\begin{array}{l}\text { G-1 } \\
\text { (U.S. Geol. Surv.) } \\
1 \\
2\end{array}$ & $\begin{array}{l}0.0334 \\
0.0194\end{array}$ & $\begin{array}{l}65 \\
65\end{array}$ & $\begin{array}{l}4.46 \times 10^{-5} \\
2.52 \times 10^{-5}\end{array}$ & $\begin{array}{l}0.134 \\
0.131\end{array}$ & $\begin{array}{l}0.140-0.207^{13} \\
0 \cdot 140-0.207^{13}\end{array}$ \\
\hline $\begin{array}{l}\text { W-1 } \\
\text { (U.S. Geol. Surv.) } \\
1 \\
2 \\
3\end{array}$ & $\begin{array}{l}0.0291 \\
0.0286 \\
0.0282\end{array}$ & $\begin{array}{l}66 \\
84 \\
66\end{array}$ & $\begin{array}{l}1.54 \times 10^{-4} \\
1.64 \times 10^{-4} \\
1.0 \times 10^{-4}\end{array}$ & Average $0 \cdot 133$ & $\begin{array}{l}0.510-0.864^{18} \\
0.510-0.864^{13} \\
0.510-0.864^{13}\end{array}$ \\
\hline $\begin{array}{l}\text { Ferrochromium Alloy } \\
\text { (U.S. Nat. Bur. } \\
\text { Stand. 64) } \\
\begin{array}{l}1 \\
2 \\
3\end{array}\end{array}$ & $\begin{array}{l}0 \cdot 0778 \\
0 \cdot 200 \\
0 \cdot 0480\end{array}$ & $\begin{array}{l}70 \\
60 \\
68\end{array}$ & $\begin{array}{l}2.0 \times 10^{-5} \\
4.5 \times 10^{-5} \\
1.05 \times 10^{-5}\end{array}$ & $\begin{array}{l}0.0367 \\
0.0380 \\
0.0320\end{array}$ & $\begin{array}{l}0.034 \\
0 \cdot 034 \\
0.034\end{array}$ \\
\hline & & & & Average 0.036 & \\
\hline
\end{tabular}

TABLE III-ACTIVATION ANALYSIS OF OTHER TYPES OF SAMPLES FOR TITANIUM*

\begin{tabular}{lc}
\hline \multicolumn{1}{c}{ Sample } & Level of Ti in sample, ppm \\
\hline Gingko leaf & $84 \pm 5 \%$ \\
Cigarette tobacco & $250 \pm 2 \%$ \\
Agate from Utah & $44 \pm 7 \%$ \\
Holbrook meteorite & $467 \pm 5 \%$ \\
Johnstone meteorite & $505 \pm 5 \%$ \\
\hline
\end{tabular}

* In each case these results represent averages of three or more determinations. Errors are standard deviation.

The primary advantage of this type of analysis for titanium is that no correction for reagent blank is necessary because only the titanium which was originally irradiated with the sample will be activated and measured in the analysis.

Acknowledgements-This work was supported in part by the U.S. Atomic Energy Commission. Thanks are due to Professor H. J. Gomberg, C. W. Ricker, and the staff of the Ford Nuclear Reactor for their help in making the irradiations. Part of the stay of one of us (C. K. K.) was supported by a training grant from the Government of Korea.

Zusammenfassung-Ein Kernreaktor wurde zur Bestimmung von Spuren Titans mittels Neutronenaktivierungsanalyse herangezogen, Eine 10-Minuten-Trennungsmethode in Verbindung mit Gammastrahlspektrometrie erlaubte die Messung des 5.8-Minuten Ti-51. Mit einem Neutronenfluss von $10^{12} \mathrm{n} \mathrm{cm}^{-2} \mathrm{Sec}^{-1}$ ist die praktische Erfassunggrenze etwa $6 \times 10^{-7} \mathrm{~g}$ Titan. 
Résumé-Un réacteur nucléaire a été utilisé pour le dosage de traces de titane par activation dans un certain nombre d'échantillons. Une séparation radiochimique rapide ne demendant que 10 minutes, associée à la spectrométrie gamma a permis le dosage du Ti 51 de 5,8 minutes de période. Avec un flux de neutrons de $10^{12}$ neutrons par $\mathrm{cm}^{2}$ et par seconde la limite de détection est de l'ordre de $6.10^{-7}$ grammes de titane.

\section{REFERENCES}

${ }^{I}$ W. A. Brooksbank, Jr., G. W. Leddicottc and J. A. Dean, Analyt. Chem. 1958, 30, 1785.

2 W. A. Brooksbank, Jr., U.S. Atomic Energy Commission Report ORNL-2226, 1956.

${ }^{3}$ W. W. Meinke, Analyt. Chem., 1959, 31, 792

${ }^{4}$ E. B. Sandell, Colorimetric Determination of Traces of Metals, Interscience Publishers, N.Y., 1959.

'D. G. Kaiser and W. W. Meinke, Talanta, 1960, 3, 255.

B J. L. Brownlee, Jr., U.S. Atomic Energy Commission Report TIS-6311 (Ph.D. Thesis), June, 1960.

${ }^{7}$ W. W. Meinke, Nucleonics, 1959, 17, No. 9, 86.

Idem, U.S. Atomic Energy Commission Report AECU-3641, November, 1957.

Idem, U.S. Atomic Energy Commission Report AECU-3887, November, 1958.

${ }^{10}$ R. S. Maddock and W. W. Meinke, U.S. Atomic Energy Commission Report AECU-4438, November, 1959.

${ }^{11}$ R. Fukai and W. W. Meinke, Limnology and Oceanography, 1962, 7, 186.

12 C. K. Kim, Nuclear Science Series Report NAS-NS-3034, The Radiochemistry of Titanium, National Research Council, Washingon 25, D.C., March, 1961.

${ }^{13}$ M. Fleischer and R. E. Stevens, Geochim. Cosmochim. Acta, 1962, 26, 525. 